\title{
The cardiovascular risk factors and health-related physical fitness of employees at General Directorate of Youth and Sport of Mazandaran Province in Iran
}

\author{
Hamid Arazi ${ }^{1 *}$, Roohollah Amin Shokouhi ${ }^{2}$, Ali Sayah ${ }^{3}$, Shima Aboutalebi ${ }^{1}$ \\ ${ }^{1}$ Department of Exercise Physiology, Faculty of Sport Sciences, University of Guilan, Rasht, Iran. \\ ${ }^{2}$ Department of Sport Sciences, Faculty of Humanities, Islamic Azad University, Rasht Branch, Rasht, Iran. \\ ${ }^{3}$ Department of Sport Sciences, Faculty of Humanities, University of Zanjan, Zanjan, Iran.
}

\begin{abstract}
The evidence shows that the sedentary life increases the risk of coronary heart disease and decreases physical fitness. However, this study aimed to evaluate the cardiovascular risk factors and health-related physical fitness of employees at General Directorate of Youth and Sport of Mazandaran Province in Iran. For this purpose, using random sampling method, 40 employees (age mean= $35.54 \pm 7.63$ years old, body mass index $=22.61 \pm 9.70 \mathrm{~kg} / \mathrm{m}^{2}$ ) at General Directorate of Youth and Sport of Mazandaran were selected as sample. Then, after collecting necessary data by questionnaire, the health-related physical fitness was measured in terms of cardiorespiratory endurance, muscular endurance, body fat percentage, strength, and flexibility. Also, the sphygmomanometer was used to measure heart rate (HR) and blood pressure (BP). Finally, $5 \mathrm{ml}$ blood was taken from subjects to evaluate cardiovascular risk factors including total cholesterol (TC), triglyceride (TG), fasting blood sugar (FBS), low density lipoprotein (LDL), and high density lipoprotein (HDL). The findings showed that there was no significant difference between TC, TG, LDL, HDL, systolic blood pressure (SBP), and diastolic blood pressure (DBP) of employees at General Directorate of Youth and Sport of Mazandaran and desirable situation. However, there was significant difference between health-related physical fitness of employees and desirable situation $(\mathrm{P}<0.05)$. It was concluded that due to undesirable situation of physical fitness of employees, it is necessary to take measures to emphasize regular exercise programs and promote their fitness and health.
\end{abstract}

Keywords. Cardiovascular diseases, health, physical fitness, physical inactivity, sports employees.

\section{Introduction}

7 he physical fitness is generally defined as capacity and ability to do daily works, especially physical activities, without early and unusual exhaustion. In sports, it is defined as ability to perform athletic activities without early and excessive exhaustion. The physical fitness is a strong predictor of health and is associated with reduction of risks of diseases such as cardiovascular disease, type 2 diabetes, and heart attack. It is considered to be an important factor in achieving higher levels of functional independence (Rimmer, 2004). The coronary-artery diseases are one of the most common causes of mortality and morbidity in various societies. At least part of this risk is due to abnormal blood fat which consists of high triglyceride, low HDL, and high density LDL (Lasker et al., 2008). It is shown that the high-density lipoprotein (HDL) increases by lifestyle changes; the high activity positively reduces the risk of coronary-artery diseases (Greenfeder, 2009). In addition, the HDL reduces platelet aggregation and adhesion and increases fibrinolysis and protease expression (Norata et al., 2005). The increased low density lipoprotein (LDL) is an independent risk factor for coronary artery disease and its reduction by 60 $\mathrm{mg} / \mathrm{dL}$ reduces the incidence of coronary artery disease by $50 \%$ over the next 2 years (Volaklis et al., 2007). The positive effects of decreased LDL and increased HDL are increasing and independent; in therapies which aim to simultaneously reduce LDL and increase HDL, the risk of vascular diseases may 
be reduced by about $60-80 \%$. Despite the fact that prescribing medications has reduced LDL and cardiovascular disease, the changes in lifestyle is the first line of treatment of most patients (United States Department of Health and Human Services, 1996).

Although the mortality rate due to cardiovascular diseases is decreased in developed countries, the statistics shows its increase by 20 to 40 percent in Iran (Hajsheikholeslami et al., 2011). According to American Heart Association, other than gender, heredity, and age, there are six other major risk factors for cardiovascular diseases which can be treated by changing lifestyle and medical treatment. These factors include smoking, disturbances in blood lipids, high blood pressure, lack of proper physical activity, overweight, obesity, and diabetes (American Heart Association, 2012). The cardiovascular diseases are not associated with a specific age or gender; all people at any age and gender may be at risk of these diseases. However, the effective and timely actions may reduce the risks and their complications.

The physical activity, exercise, and active lifestyle contribute to maintenance and promotion of health, especially prevention of coronary artery diseases. This may be due to favorable changes or preservation of lipids and apolipoproteins levels at desirable level by regular exercises. Therefore, it is inevitable to include a sports program in daily activities of patients and healthy people (Haghighi et al., 2005; Lozoff et al., 1991). Although the exact mechanism of CHD risk reduction due to physical activity is not known, it seems to influence risk factors and reduces blood pressure, LDL-C, total cholesterol (TC), and triglyceride (TG), and increases HDL-C and some other physiological effects such as increased heart rate and coronary circulatory capacity (Gharakhnlu et al., 2003; Kordi et al., 2004).

There are some studies on relationship between physical fitness and cardiovascular risk factors. However, there is no studies on lifestyle of a group of people who are expected to be more active and have active lifestyle. Azizi et al. (2013) examined the relationship between physical activity level and cardiovascular risk factors among 30 male students and concluded that there is negative significant correlation between physical activity level and blood cholesterol and LDL levels. However, there was no significant relationship between physical activity level and blood HDL and TG levels. On the other hand, the findings showed that there is a negative and significant correlation between physical activity level and fat mass, body fat percentage, and body mass index. Also, Vazgen et al. (2012) conducted a research on a group of 50-60 year old men in Isfahan and compared them with existing norms to examine their health-related physical fitness. The findings showed that the subjects were not in good situation in terms of cardiovascular endurance, strength, and muscular endurance compared with existing norms; however, they had a relatively good physical flexibility. On the other hand, Gholipour et al. (2012) studied the prevalence of cardiovascular risk factors among students at Sharif University of Technology and concluded that the prevalence of overweight and obesity was $19.29 \%$ and prevalence of central obesity based on waist indicator was $21.97 \%$. Also, high levels of triglyceride and blood pressure were observed in $12.21 \%$ and $14.8 \%$ of subjects, respectively. There were at least two cardiovascular risk factors in $87 \%$ of subjects.

Since physical activity and fitness is usually low among employees and the employees should attend with greater passion and vitality in workplace, the targeted planning is necessary to improve their physical fitness and mental health. Accordingly, considering that the employees at General Directorate of Sports and Youth in Mazandaran have sport-related professions and are considered to have a good knowledge of effects of physical activity, this question arises: whether these individuals are in a desirable situation in terms of health-related physical fitness and cardiovascular risk factors? The answer to this question may definitely determine their real situation and provide strategies for preventing diseases and promoting their health. Therefore, this study aims to evaluate the cardiovascular risk factors and health-related physical fitness of employees at General Directorate of Youth and Sport in Mazandaran.

\section{Methods}

This was a descriptive, field, and laboratory study. It aimed to evaluate the cardiovascular risk factors and health-related physical fitness of employees at General Directorate of Youth and Sport in Mazandaran. The population consisted of all employees at General Office of Sports and Youth in Mazandaran. Using random sampling method, 40 employees were selected as sample. 
Table 1

Individual characteristics of subjects.

\begin{tabular}{lc}
\hline Variables & Mean \pm SD \\
\hline Age $($ year $)$ & $35.54 \pm 7.63$ \\
Height $(\mathrm{cm})$ & $175.41 \pm 6.38$ \\
Weight $(\mathrm{kg})$ & $75 \pm 18.47$ \\
Body mass index $\left(\mathrm{kg} / \mathrm{m}^{2}\right)$ & $22.61 \pm 9.70$ \\
\hline
\end{tabular}

After completing consent form, medical records questionnaire, and physical activity readiness questionnaire, the field tests were conducted to assess health-related physical fitness. In addition, the blood samples were taken from subjects to evaluate cardiovascular risk factors (HDL, LDL, FBS, TG, and TC).

The Seca Scale (made in Germany) with a sensitivity of $0.1 \mathrm{~kg}$ was used to measure the weight of subjects. The height of subjects was measured by wall stadiometer. The fat percentage of subjects was estimated by using Caliper (Lafayette, USA) to measure thickness of chest, abdomen, and thigh fat layers and placing them in Jackson and Pollack's Body Fat Percentage Equation (Jackson et al., 1978):

Body fat percentage of men $=1.10938-(0.0008267$ $x$ the sum of the chest, abdomen and thigh measurements in millimeters $)+(0.0000016 \times$ the square of the sum of the chest, abdomen and thigh measurements in millimeters $)-(0.0002574 \times$ age $)=$ body density 450

Body Fat Percentage $(\%)=(495 /$ Body Density $)-$

The BMI formula was used to determine body mass index of subjects. According to BMI formula, the numbers less than 19 are low-weight, 19-25 are acceptable, and 25-30 are overweight, and over 30 are obese.

$$
\text { BMI }=\text { Weight }(\mathrm{Kg}) / \text { Height }^{2}\left(\mathrm{~m}^{2}\right)
$$

The standard mercury sphygmomanometer (Japan) was used to measure blood pressure at rest in two steps (10 minutes interval). The systolic blood pressure equal to $120 \mathrm{mmHg}$ and diastolic blood pressure equal to $80 \mathrm{mmHg}$ were considered to be normal. The systolic blood pressure between 120-129 $\mathrm{mmHg}$ and diastolic blood pressure between $80-89$ $\mathrm{mmHg}$ were classified as borderline. The systolic blood pressures equal to or greater than $140 \mathrm{mmHg}$ and diastolic blood pressure equal to or greater than $90 \mathrm{mmHg}$ were categorized as high blood pressure.
The blood sample (5 milliliters) was taken from each subject at fasting ( 12 hours) in similar conditions (at $8 \mathrm{am}$ ). The blood plasma was separated using a centrifuge device. Then, the LDL, HDL, TC, TG, and FBS values were examined and tested.

The glucose oxidase method was used to measure fasting glucose. The intensity of light absorption was measured by spectrophotometry. The abnormal level was considered to be equal to or greater than 110 $\mathrm{mg} / \mathrm{dl}$. For upper body muscle strength test, the chest press was used; the subjects laid down the press table and lifted the weights in proportion to their strength for 3 to 5 sets at time interval of 3 minutes. Finally, the weight that could be lifted only once was recorded as maximum repetition. To measure the strength of lower body, the subjects seated on leg press device and applied their maximum strength for 3 to 5 sets. The highest lifted weight in one repetition was recorded as maximum lower body strength of subjects.

The flexibility board was used to measure flexibility. So, the subjects sat down on floor and stretched their hands on top of their head forward; the number which was touched by finger was recorded as flexibility number. This test was repeated three times and the highest number was considered as record. In cardio-respiratory endurance test, the subjects fully warmed up and ran 1600 meter. The time interval between starting point and end point was recorded in minutes and seconds. The push-up test was used to measure muscular endurance. The unit for assessing muscular endurance was counting the number of repetitions. The number of repetitions was recorded in one minute.

\section{Data analysis}

The mean, dispersion, and standard deviation indices were used to describe data. The KolmogorovSmirnov test was used to evaluate the distribution of data. Also, t-test was used to test hypotheses. The significance level was considered to be $p<0.05$. The data were analyzed using SPSS software, version 20. The tables and charts were created by Excel software.

\section{Results}

The measured features in this study included cardiovascular risk factors (cholesterol, triglycerides, high density lipoprotein, low density lipoprotein, body fat percentage, systolic blood pressure, 
diastolic blood pressure, and blood glucose) and health-related physical fitness factors (flexibility, cardio-respiratory endurance, upper body strength, muscular endurance, and lower body strength). The findings showed that the employees at General directorate of Sports and Youth of Mazandaran were significantly far from desirable situation in some health-related physical fitness factors and cardiovascular risk factors such as cardio-respiratory endurance $(p=0.039)$, muscular endurance $(p=$ $0.037)$, upper body strength $(p=0.005)$ and lower body strength $(\mathrm{P}=0.005)$, body fat percentage $(p=$ $0.004)$, and systolic blood pressure $(p=0.01)$. However, there was no significant difference between their cholesterol $(p=0.154)$, triglyceride ( $p=$ $0.12)$, and diastolic blood pressure $(p=0.4)$ and desirable situation; but numerically, they were near the risk area.

\section{Table 2}

Values of cardiovascular risk factors and health-related physical fitness of employees at General Directorate of Sports and Youth in Mazandaran.

\begin{tabular}{lcc}
\hline Variables & Mean \pm SD & Norm \\
\hline Cholesterol (mg/dl) & $187 \pm 33.2$ & 199 \\
Triglyceride (mg/dl) & $180 \pm 4.9$ & 199 \\
High density lipoprotein (mg/dl) & $42.5 \pm 4.7$ & 36 \\
Low density lipoprotein (mg/dl) & $123 \pm 4.5$ & 129 \\
Systolic blood pressure (mmHg) & $135 \pm 8.98^{*}$ & 120 \\
Diastolic blood pressure (mmHg) & $82 \pm 5.89$ & 80 \\
Blood glucose (mg/dl) & $83 \pm 6.69$ & 110 \\
Cardiac - Respiratory endurance (min) & $8.23 \pm 1.01^{*}$ & 6 \\
Muscular endurance (rep) & $23^{*}$ & 35 \\
Upper body strength (kg) & $52^{*}$ & 60 \\
Lower body strength (kg) & $120 \pm 15^{*}$ & 140 \\
Body fat (\%) & $19 \pm 9.59^{*}$ & 17 \\
Flexibility (cm) & $23^{*}$ & 30 \\
\hline
\end{tabular}

* Significant relative to desirable value at $p<0.05$

** Numbers in norms column are minimum of desirable domain.

\section{Discussion}

The cardiovascular diseases (CVD) have increased in recent decades. Today, the cardiovascular diseases are one of the leading causes of death in the world. Nearly half of deaths in industrialized countries and $25 \%$ in developing countries are related to coronary heart diseases. This study aimed to evaluate the cardiovascular risk factors and health-related physical fitness of employees at General Directorate of Youth and Sport in Mazandaran.

The first finding of this study showed that there is no significant difference between blood cholesterol of employees and desirable situation. This is consistent with findings of Shields et al. (2010) and inconsistent with findings of Azizi et al. (2013) and Santana et al. (2003). Esmail Nansab et al. (2012) studied the correlation between physical activity and coronary heart risk factors among students and concluded that there is a negative and significant correlation between physical activity level and cholesterol level. Nourbakhsh (2012) studied the correlation between physical activity and some cardiovascular risk factors among male managers and found that the cholesterol, triglyceride, low density lipoprotein, and fat percentage of male managers in Shahid Chamran University were significantly more than non-managers. The reasons for inconsistency of findings of this study with some research may include age, gender, training period, physical activity level (Azizi et al., 2013), levels of thyroid and gender hormones (Asad, 2013), type of subjects, health situation of participants, and etc. (Naghizadeh et al., 2009). On the other hand, due to close relationship between nutrition and cholesterol level, it is likely that a significant part of diet of subjects includes healthy foods such as fruits and vegetables, low-fat dairy products, grains, fishes, and low-fat foods (Lichtenstein et al., 2006; Mosca et al., 2004); therefore, their blood cholesterol levels are maintained at normal levels.

The findings also showed that there is no significant difference between blood triglyceride level of employees and desirable situation. This is consistent with findings of Azizi et al. (2013), Vazgen (2012), Golipour et al. (2012), and Mirzai et al. (2010). However, it is inconsistent with findings of Baker et al. (2007). In order to explain maintenance of TG levels at natural range, it may be said that the subjects (employees of General Directorate of Sports and Youth in Mazandaran) were working in office for considerable hours of day; this has likely prevented them from consuming lowvolume and high-calorie foods. Of course, the lifestyle, diet, and physical activity are also influential factors in health of individuals (Santa et al., 2003).

The findings showed that there is no significant difference between blood HDL and LDL levels of 
employees and desired situation. This is consistent with findings of Shields et al. (2010); however, it is inconsistent with findings of Resaland et al. (2011) and Naghizadeh et al. (2009). This inconsistency may be due to difference in age of subjects or even measurement errors. The age range of studied subjects is within adulthood range and maintaining blood HDL and LDL levels is logical.

According to other finding, there is no significant difference between diastolic blood pressure and desirable situation. However, there was a significant difference in systolic blood pressure of employees. This is consistent with findings of Azizi et al. (2013), Vazgen (2012) and Gholipour et al. (2012). However, it is inconsistent with findings of Drygas et al. (2000). Gareth et al. (2003) stated that the low level of physical activity is directly associated with high blood pressure in men. On the other hand, the data analysis showed that the body fat percentage of subjects was significantly different from desirable situation. Since the accumulation of fat in abdominal region (abdominal obesity) has a close relationship with metabolic factors and high blood pressure (Mirzaei et al., 2010), it may be concluded that the increased body fat percentage of employees at General Directorate of Sports and Youth in Mazandaran has contributed in increased diastolic blood pressure.

According to the findings, the fasting blood glucose of employees was normal; only one person reported glucose $126 \mathrm{mg} / \mathrm{dl}$ which did not make a significant difference. This is consistent with findings of Golipur et al. (2011). However, it is inconsistent with findings of Yousefi pour et al. (2015). In order to explain this finding, it was said that it is likely these people eat breakfast and go to office and after the end of their work and office hours, they return home for having lunch. Due to high working hours and lack of extra time, they do not eat snacks and foods which have simple carbohydrate.

The findings showed that there is a significant difference between body fat percentage of employees and desirable situation. This is consistent with findings of Katzmarzik et al. (1999), Vazgen (2012), and Gholipour et al. (2012). However, it is inconsistent with findings of Suzuki et al. (1998) and Tusik et al. (2000). The regular exercise increases body's energy need. When more energy is received, the exercise increases body's metabolism and energy consumption. Then, if physical activity is low and the received energy is more than needed level, the excess energy may increase body fat percentage. Considering the working situations of employees, this explanation is logical; the employees spend most of their time in office and have low activity level. It should be noted that other factors including reduced secretion of growth hormone, reduced activity of sex hormones, and reduced metabolism may also contribute to increased body fat; however, the most important factor is the low level of physical activity of employees (Stewart, 2005; Kavanagh et al., 1977).

According to the findings, it was shown that there is significant difference between muscular endurance of employees at General directorate of Sports and Youth in Mazandaran and desirable situation. This is consistent with findings of Valipour Dehnou et al. (2015) and Robinson et al. (1995). However, it is inconsistent with findings of Grassia Lopez et al. (2007). The physical activity creates nerve adaptations in body and stimulates proteins buildup and therefore, increases muscle endurance (Valipour Dehnou et al., 2015). However, this low muscle endurance in employees may be due to lack of physical activity or low physical activity.

The findings showed that there is a significant difference between cardio-respiratory endurance of employees at General directorate of Sports and Youth in Mazandaran and desirable situation. This is consistent with findings of Salami (2004) and Grant et al. (1992). However, it is inconsistent with findings of Reddy et al. (1991). The exercise with a severity of over $60 \%$ of maximum heart rate is required to increase cardio-respiratory endurance (Salami, 2004); in light activities, there are no necessary adaptations to improve cardio-respiratory endurance. As noted earlier, the studied employees spend many hours without physical activity and are busy doing their work sitting at the table. This inactivity has a negative effect on their cardio-respiratory endurance; this is one of the most important factors affecting a person's health.

Also, the findings suggested that there is a significant difference between muscle strength of employees at General Directorate of Sports and Youth in Mazandaran and desirable situation. This is consistent with findings of Vazgen et al. (2011) and Noorshahi et al (2009). The studies have shown that with increasing of age, the muscle fibers are degraded and this leads to muscle atrophy (Frontera et al., 1988; Commodari et al., 2008). The physical activity and exercise use some physiological mechanisms such as increasing cross-sectional area 
of muscle, changing muscle structure, increasing motor units, and stimulating motor units with more frequencies to increase muscle strength (Kraemer et al., 2002; Grandys et al., 2008). Due to lack of physical activity or low level activity, the studied employees had low body strength.

According to findings, there is a significant relationship between flexibility of employees at General Directorate of Sports and Youth in Mazandaran and desirable situation. This is inconsistent with findings of Vazgen et al. (2012) and Fathi et al. (2014). It is likely that the activity type, sitting condition, and daily routine habits of studied employees (Vazgen et al., 2012) have prevented them from retaining flexibility and ultimately has led to significant difference between their flexibility and desirable situation.

The physical health and good physical situation are important in people's lives. Accordingly, the physical activity has been specially considered in various physiological, psychological, social, and mental and cultural health dimensions. The studies have reported that the physical activities may control factors such as obesity, inactivity, injuries, nutritional disorders, and development of physical fitness factors (Brown, 2005). Although the benefits of regular physical activity are clear, there are probably several reasons for neglecting physical activity by employees such as lack of suitable facilities for sports activities, lack of time, energy, and motivation, illness, fear of injury, and lack of skill (Sallis et al., 2009).

According to findings of this study, the sport activity may play an important role in improving health of employees at General Directorate of Sports and Youth in Mazandaran. In order to raise their level of health and quality of life, therefore, the employees are recommended to perform a regular training program in their daily routines. This action may also be beneficial in reducing the risk of cardiovascular diseases and chronic illness due to increased levels of physical activity and reduced body fat.

On the other hand, the authorities may also use various strategies such as holding workshops and lecture sessions to raise awareness of employees about benefits of regular sport activities to increase their health level and reduce the risk of cardiovascular diseases. They may also adopt necessary measures to include regular sporting activities in working hours of employees.
Conflict of Interest: The authors declare that they have no any conflict of interests.

\section{References}

American Heart Association. Risk factors and coronary heart disease. AHA scientific Position. Available: http://www.heart.org/heartorg/condition/HeartAttack/U nderstand Your Risk of Heart Attack/Understand -yourRisk- of-Heart Attack_UCM_002040_Article.jsp. Accessed February 10, 2012.

Asad M. Effect of 8 weeks aerobic, resistance and concurrent training on cholesterol, LDL, HDL and cardiovascular fitness in obesity male. Applied Research of Sport Management and Biology, 2013; 5(3): 57-64.

Azizi M, Hoseini R. Relationship between physical activity level and risk factors of cardiovascular disease in male college students. J Practical Studies of Biosciences in Sport, 2013; 1(2): 110-123.

Baker JL, Olsen LW, Sorensen ThI. Childhood body-mass index and the risk of coronary heart disease in adulthood. N Eng J Med, 2007; 357(23): 2329-2337.

Brown MJ. Fitness and its effects on the military: DTIC Document 2005.

Canadian Standardized Test of Fitness (CSTF) Operations Manual. Third Edition. Ottawa: Fitness and Amateur Sport, Government of Canada, 1986.

Commodari E, Guarnera M. Attention and aging. Aging Clin Exp Res, 2008; 20(6): 578-584.

Drygas W, Kostka T, Jegier A, Kuski H. Long-term effects of different physical activity levels on coronary heart disease risk factors in middle-aged men. Int J sports Med, 2000; 21(04): 235-241.

Esmail nasab N, Etemad Z. The Relationship between physical activity and some risk factors for coronary heart (CHD) in students. Sci J Kurdistan Univ Med Sci, 2012; 17(1): 25-35.

Fathi K, Ghorbani F, Heidarimoghadam R, mojtahedi H. The effect of six- week aerobic step training on cardiovascular fitness, body composition, flexibility, anaerobic power and quality of life of female students of Isfahan University. J Ergonomics, 2014; 2(2): 29-37.

Frontera WR, Meredith CN, O'Reilly KP, Knuttgen HG, Evans WJ. Strength conditioning in older men: skeletal muscle hypertrophy and improved function. J Appl Physiol, 1988; 64(3): 1038-1044.

Garcĺa-1Ópez D, DePaz JA, Moneo E, Jiménez R, Bresciani G, Izquierdo M. Effects of short vs. long rest period between sets on elbow-flexor muscular endurance during resistance training to failure. J Strength Cond Res, 2007; 21(4): 1320-1324.

Gharakhnlu R, Rajabi H, Nikbakht H, Alijani E, Gaeni A. Basic concepts in science of exercise and physical fitness. National Olympic Committee, 2003: 12-15.

Gholipour M, Tabrizi A. Prevalence of cardiovascular risk factors among students of Sharif University of Technology. Cardiovasc Nurs J, 2012; 1(2): 48-56. 
Grant S, Aitchison T, Pettigrew AR, Orrell JM. The effects of a university fitness program on health-related variables in previously sedentary males. Br J Sports Med, 1992; 26(1): $39-44$.

Grandys M, Majerczak J, Duda K, Zapart-Bukowska J, Sztefko K, Zoladz JA. The effect of endurance training on muscle strength in young, healthy men in relation to hormonal status. J Physiol Pharmacol, 2008; 59(7): 89-103.

Greenfeder S. Emerging strategies and agents to lower cardiovascular risk by increasing high density lipoprotein cholesterol levels. Curr Med Chem, 2009; 16(2): 144-156.

Haghighi A, balavi A, HamediNia M, Askari R. The effects of aerobic training with different intensities on some cardiovascular risk factors in young girls. J Sport Biosciences, 2005; 13(13): 63-84.

Hajsheikholeslami F, Hatami M, Hadaegh F, Ghanbarian A, Azizi F. Association of educational status with cardiovascular disease: Teheran Lipid and Glucose Study. Int J Public Health, 2011; 56(3): 281-287.

Jackson AS, Pollock ML. Generalized equations for predicting body density of men. Br J Nutr, 1978; 40(3): 497-504.

Katzmarzyk PT, Malina RM, Bouchard C. Physical activity, physical fitness, and coronary heart disease risk factors in youth: the Quebec Family Study. Prev Med, 1999; 29(6): 555-562.

Kavanagh T, Shephard RJ. The effects of continued training on the aging process. Ann N Y Acad Sci, 1977; 301(1): 656-670.

Kordi M, Siahkuhian M, Havanlu F, Zollfeghari M. practical exams of respiratory cardiac preparation: institute of education, research management and planning 2004; 4-19.

Kraemer WJ, Adams K, Cafarelli E, Dudley GA, Dooly C, Feigenbaum MS, Hoffman JR. American College of Sports Medicine position stand. Progression models in resistance training for healthy adults. Med Sci Sports Exerc 2002; 34(2): 364-380.

Lasker DA, Evans EM, Layman DK. Moderate carbohydrate, moderate protein weight loss diet reduces cardiovascular disease risk compared to high carbohydrate, low protein diet in obese adults: A randomized clinical trial. J Nutr Metab, 2008; 5(1): 30.

Lichtenstein AH, Appel LJ, Brands MC, Merced DS, Franch HA, Howard B. Diet and lifestyle recommendations revision 2006. Circulation, 2006; 114(1): 82-96.

Lozoff B, Jimenez E, Wolf AW. Long-term developmental outcome of infants with iron deficiency. N Engl J Med, 1991; 325(10): 687-694.

Mackenzie B. Leg press test Available from: http://www.brianmac.co.uk/1press.htm, 2000.

Mirzaei B, Faraji H, Allami A, Bab L. Evaluate and compare the features of body composition based on national norms for students of University of Gilan and Kurdistan. Sport Biomotor Sci, 2010; 2(3): 38-47.

Mosca L, Appel LJ, Benjamin EJ, Berra K, Chandra SN, Fabunmi $\mathrm{RP}$, Judelson DR. Evidence-based guidelines for cardiovascular disease prevention in women. Arterioscl Throm Vasc, 2004; 24(3): e29-e50.
Naghizadeh H, Afzalpour M, Akbarzadeh H. Comparison of antioxidant characteristics and cardiovascular risk factors in zourkhaneh (traditional wrestling) sportsmen and nonsportsmen. J Shaheed Sadoughi Univ Med Sci, 2009; 17(4): 262-269.

Nielsen GA, Andersen LB. The association between high blood pressure, physical fitness, and body mass index in adolescents. Prev Med, 2003; 36(2): 229-234.

Norata GD, Catapano AL. Molecular mechanisms responsible for the antiinflammatory and protective effect of HDL on the endothelium. Vasc Health Risk Manag, 2005; 1(2): 119129 .

Nourbakhsh M. Investigating the relationship between physical activity level and cardiovascular risk factors in male managers at Shahid Chamran University. J Cardiovascular and Activeness, 2003; 1: 27-41.

Nourshahi M, Rahmani H, ArefiRad T, Zahedi H, Rajaeyan A. Correlation of Mountaineering With Cardiovascular and Physical health in the Elderly. Iran J Aging (Salmand), 2009; 4(3) [In Persian].

Pollock ML, Wilmore JH, Fox SM. Health and fitness through physical activity. John Wiley \& Sons Inc., 1978.

Ready AE, Fitzpatrick DW, Boreskie SL, Hrycaiko DW. The response of obese females to low impact exercise and diet counselling. J Sports Med Phys Fitness, 1991; 31(4): 587595.

Resaland GK, Anderssen SA, Holme IM, Mamen A, Andersen LB. Effects of a 2-year school-based daily physical activity intervention on cardiovascular disease risk factors: the Sogndal school-intervention study. Scand J Med Sci Sports, 2011; 21(6): e122-e131.

Rimmer JH, Heller T, Wang E, Valerio I. Improvements in physical fitness in adults with Down syndrome. Am J Ment Retard, 2004; 109(2): 165-174

Robinson JM, Stone MH, Johnson RL, Penland CM, Warren BJ, Lewis Rd. Effects of different weight training exercise/rest intervals on strength, power, and high intensity exercise endurance. J Strength Cond Res, 1995; 9(4): 216-221.

Salami F. Investigating the changes in physical fitness, motion during the first semester of female students of Tarbiat Moallem University. J Movement Science \& Sports, 2004; 2(4): 47-60.

Sallis JF, Bowles HR, Bauman A, Ainsworth BE, Bull FC, Craig CL, Matsudo V. Neighborhood environments and physical activity among adults in 11 countries. Am J Prev Med, 2009; 36(6): 484-490.

Santa CH, Fernhall B, Baptista F, Mendes M, Sardinha LB. Effect of a one-year combined exercise training program on body composition in men with coronary artery disease. Metabolism, 2003; 52(11): 1413-1417.

Shields M, Tremblay MS, Laviolette M, Craig CL, Janssen I, Gorber SC. Fitness of Canadian adults: Results from the 2007-2009 Canadian health measures survey. Health Reports, 2010; 21(1).

Stewart KJ. Physical activity and aging. Ann N Y Acad Sci, 2005; 1055: 193-206. 
Suzuki I, Yamada H, Sugiura T, Kawakami N, Shimizu H. Cardiovascular fitness, physical activity and selected coronary heart disease risk factors in adults. J Sports Med Phys Fitness, 1998; 38(2): 149-157.

The National Institues of Health (NIH), and the National Heart, Lung, and Blood institute (NHLBI). Third Report of the Expert panel on Detection, Evaluation and Treatment of High Blood cholesterol in Adult (Adult Treatment panel III) (Washington, DC: U.S Government printing office, 2002.

Twisk JW, Kemper HC, Van MECHELEN W. Tracking of activity and fitness and the relationship with cardiovascular disease risk factors. Med Sci Sports Exerc, 2000; 32(8): 1455-1461.

United States Department of Health and Human Services. Physical Activity and Health: A Report of the Surgeon General. Washington, DC: US Government Printing Office: 1996. DHHS publication [S/N 017-023-00196-5]. [24 http://www.cdc.gov/nccdphp/sgr/sgr.htm]; [Cited 2004 August 15]. Available from: URL.

Valipour Dehnou V, Mansournejad H, Gharakhanlou R, Sharafi F. Response of Strength, Power and Muscle Endurance to Resistance Training with Different Rest Intervals. J Sport Biosciences, 2015; 7(1): 77-91.

Vazgen M, Marandi M, Mojtahedi H, Ghasemi Gh. The Evaluation of Health-Related Physical Fitness Status of Men aged 5065 in Isfahan and compare them with existing norms. J Sport Biosciences, 2012; (14): 111-127.

Volaklis KA, Spassis ATh, Tokmakidis SP. Land versus water exercise in patients with coronary artery disease: effects on body composition, blood lipids, and physical fitness. Am Heart J, 2007; 154(3): 560- 566 .

Yousefi pour P, Tadibi V, Behpour N, Parno AH, Delbari ME. Effects of aerobic exercise on glucose control and cardiovascular risk factor in type 2 diabetes patients. Med J Mashhad Univ Med Sci, 2015; 57(9): 976-984. 